\title{
5
}

\section{Strategies to Increase Energy Efficiency of Centrifugal Pumps}

\author{
Trinath Sahoo \\ M/S Indian Oil Corporation ltd., Mathura Refinery, \\ India
}

\section{Introduction}

As the pie chart below ndicates, the LCC of a typical industrial pump over a 20 year period is primarily made up of maintenance and energy costs.

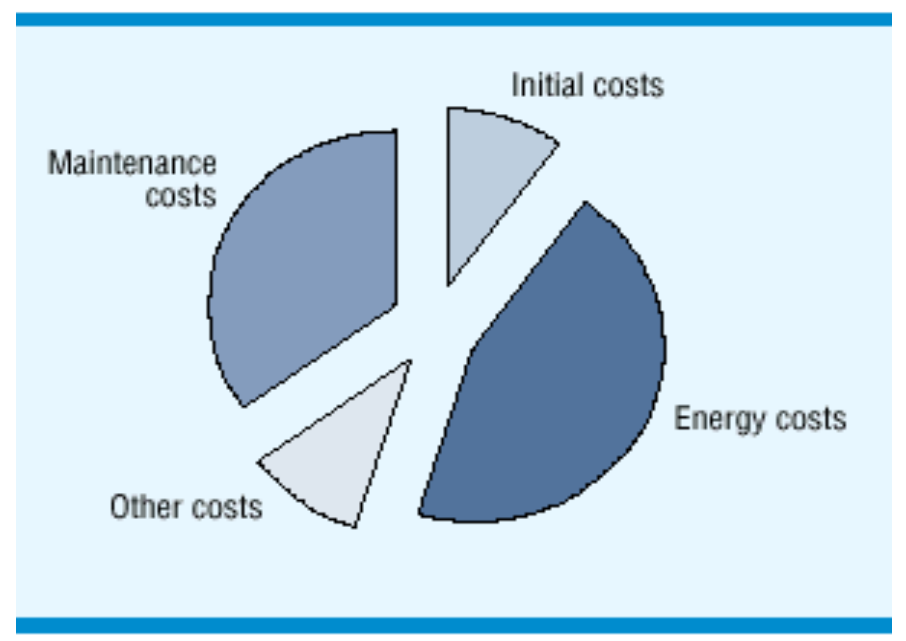

Fig. 1. Life cycle cost of centrifugal pump

Energy cost is highest of the total cost of owning a pump. Centrifugal pumps consume, depending on the industry, between 25 and $60 \%$ of plant electrical motor energy.

\begin{tabular}{|l|l|}
\hline INDUSTRY & $\begin{array}{l}\text { PUMP ENERGY } \\
\text { (\% of Total Motor Energy) }\end{array}$ \\
\hline Petroleum & $59 \%$ \\
Pulp \& Paper & $31 \%$ \\
Chemical & $26 \%$ \\
\hline
\end{tabular}

Proper matching of pump performance and system requirements, however, can reduce pump energy costs by an average of 20 percent in many cases. The process of specifying the 
right pump technology for an application in facilities should go well beyond first cost, but in too many cases, it does not. Such a shortsighted approach can create major, long-term problems for organizations.

In the process industries, the purchase price of a centrifugal pump is often $5-10 \%$ of the total cost of ownership. Typically, considering current design practice, the life cycle cost (LCC) of a 100 horsepower pump system, including costs to install, operate, maintain and decommission, will be more than 20 times the initial purchase price. In a marketplace that is relentless on cost, optimizing pump efficiency is an increasingly important consideration.

Once the pump is installed, its efficiency is determined predominately by process conditions. The major factors affecting performance includes efficiency of the pump and system components, overall system design, efficient pump control and appropriate maintenance cycles. To achieve the efficiencies available from mechanical design, pump manufacturers must work closely with end-users and design engineers to consider all of these factors when specifying pumps.

Analysis of different losses encountered in pump operation:-

1. Mechanical friction loss between fixed and rotating parts:-

The main components are:-

- $\quad$ The external sleeve, ball or roller journal bearings.

- The internal sleeve bearings.

- Thrust bearings.

- The gland, neck bush and packing rings.

The proportion of total mechanical loss contributed by each of these will depend upon the type and condition of the pump. Proper lubrication of the bearings and glands shall reduce the frictional losses.

2. Disc friction loss between the liquid and the external rotating faces of the rotor discs:-

In principle the parts concerned here are all those rotating surfaces of the pump in contact with the liquid that do not actually take share in guiding the liquid. Such elements are:-

- The external faces of the rotor discs or shroud.

- The outer edges of the shroud.

- $\quad$ The edges of the sealing rings.

- $\quad$ The whole surface of balanced discs.

By measuring the power needed to drive the disc in a variety of conditions it appears that this power loss depends upon rotational speed, disc diameter, roughness of the sides of the discs and inner walls of the casing, the density and viscosity of the liquid and axial clearance between the disc and casing.

The axial clearance affect the power loss. Any element of liquid in contact with revolving disk will be dragged round with it, at least for a short distance and during this journey the element will necessarily be subjected to centrifugal force. This will induce it to slide outwards. Other elements from the main body of the liquid will flow into replace the original one and hence additional kind of flow will be set up as shown in fig. below. 


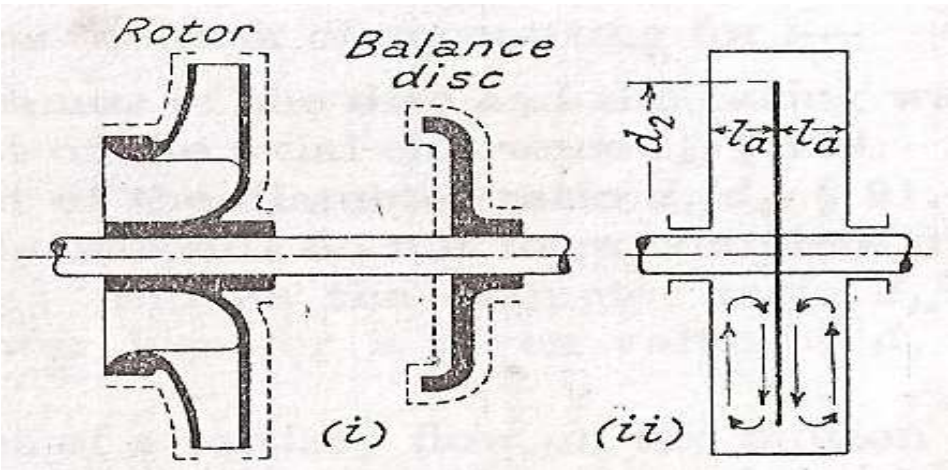

Fig. 2. Diagaram showing areas subject to disc friction loss, etc.

That is the frictional impulsion has created on a very small scale the pumping effect that the direct thrust of the impeller blades creates on an effective scale.

But it seems likely that in the space between disc and casing, the axial distance $l_{a}$ will influence both the radial and tangential velocity components. If this distance is large it will be easy for relatively large amounts of liquid to become involved in the secondary circulation and thereby to steal energy from the disc. But if the distance is small, the energy should be less.

The above study shows that in comparable conditions and increase in the axial clearance causes an increase in the power loss.

Hence it can be minimized by having as small axial clearance as possible so as to improve efficiency

3. The leakage power loss:-

The leakage liquid is bled off the main stream at a number of points, each at different pressures. Leakage may occur at other region than sealing rings:-

- Through lantern rings of liquid sealed stuffing boxes.

- $\quad$ Past the balance disc of multistage pumps.

- Past the neck bushes in the diaphragm of multi-stage pumps.

- Past the main glands/mechanical seals to waste.

In normal pumps only the leakage past the balance discs of multistage pumps can be measured and the pressure head at the leak off points is fairly well known. The leakage thru the glands / mechanical seals can be reduced by attending these leakage from time to time.

4. Hydraulic power loss:-

if we have calculated the values of mechanical loss $P_{b}$, the disc friction loss $P_{d}$ and leakage loss $\mathrm{P}_{\mathrm{l}}$, then we can assert that the residual energy $\mathrm{P}_{\mathrm{s}^{-}} \mathrm{P}_{\mathrm{b}}-\mathrm{P}_{\mathrm{d}}-\mathrm{P}_{1}$ must wholly be transferred to the main stream of liquid flowing through the pump. There is no where else for it to go. But this is a very different thing from saying that the liquid receives the corresponding net energy increment during its passage from suction flange to delivery flange. The difference between the two quantities is what we call hydraulic power loss $\left(\mathrm{P}_{\mathrm{h}}\right)$, it can be computed in this way. 
Energy En is transferred to the liquid is utilized in imparting tangential acceleration to the liquid elements.

Unit weight of liquid will receive $\left(\mathrm{V}_{\mathrm{n}} \mathrm{V}_{2} / \mathrm{g}\right)$ units of energy as there are $\mathrm{W}$ units of liquid effectively flowing per second it follows that

$$
\left(\mathrm{W} / \mathrm{K}_{\mathrm{p}}\right) *\left(\mathrm{~V}_{\mathrm{n}} \mathrm{V}_{2}\right) / \mathrm{g}=\mathrm{P}_{\mathrm{s}}-\mathrm{P}_{\mathrm{b}}-\mathrm{P}_{\mathrm{d}}-\mathrm{P}_{1}=\mathrm{P}_{\mathrm{w}}+\mathrm{P}_{\mathrm{h}}
$$

where $V_{n}$ is actual whirl component, $V_{2}$ is tangential velocity of liquid and $k_{p}$ represents energy per second corresponding to one horse-power.Now the net energy increment per unit weight of liquid is represented by $\mathrm{He}$ and the net power received, W.H.P or $\mathrm{P}_{\mathrm{w}}$ is $\mathrm{WH}_{\mathrm{e}} / \mathrm{K}_{\mathrm{p}}$.

Therefore hydraulic power loss Ph can be written

$$
\mathrm{P}_{\mathrm{h}}=\left(\mathrm{W} / \mathrm{K}_{\mathrm{p}}\right)^{*}\left\{\left(\mathrm{~V}_{\mathrm{n}} \mathrm{V}_{2} / \mathrm{g}\right)-\mathrm{H}_{\mathrm{e}}\right\}
$$

And the hydraulic efficiency

$$
\eta=\left[\mathrm{H}_{\mathrm{e}} /\left(\mathrm{V}_{\mathrm{n}} \mathrm{V}_{2} / \mathrm{g}\right)\right]=\mathrm{P}_{\mathrm{w}} /\left(\mathrm{P}_{\mathrm{w}}+\mathrm{P}_{\mathrm{h}}\right)
$$

\section{Losses under reduced and increased flow condition}

An examination of inlet velocity triangle shows that additional energy losses are now to be reckoned with in increase flow or reduced flow conditions.

a. In Rotor :

If the blade tips were made tangential to the designed inlet relative velocity vr1, they cannot be at the same time be tangential to the modified velocities vr1c or vr1d. Because of this eddies may form.
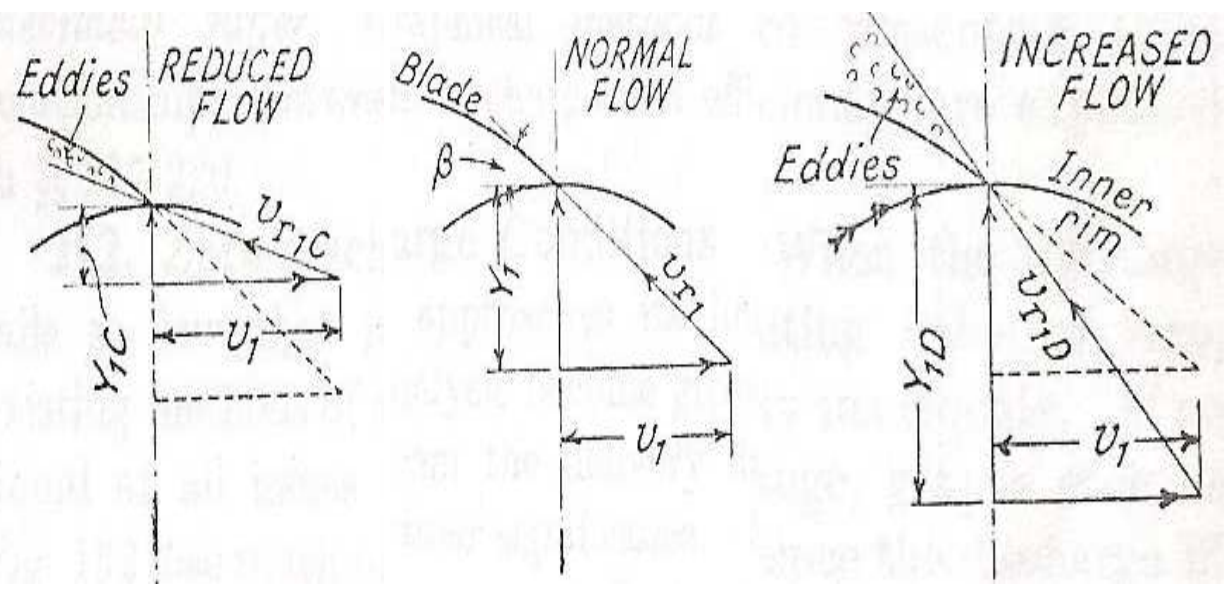

Normal and distorted inlet velocity diagrams.

When the state of flow is below normal, there may be a tendency for the liquid stream in each of impeller passages to concentrate near the front of the blades, leaving a more or less 
dead space near the back of the blades, that in regard to effective forward motion but alike and its capacity to waste energy.

b. In the Recuperator :-

When the pump discharge is reduced there will be additional energy losses. While the velocity of the liquid leaving the impeller and entering the volute is above normal yet the mean velocity in the volute itself must be below normal. Thus the essential condition for maximum efficiency of energy conversion can no longer apply.

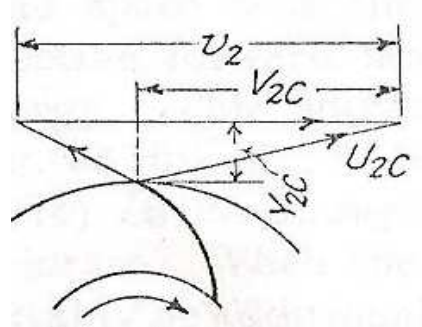

REDUCED

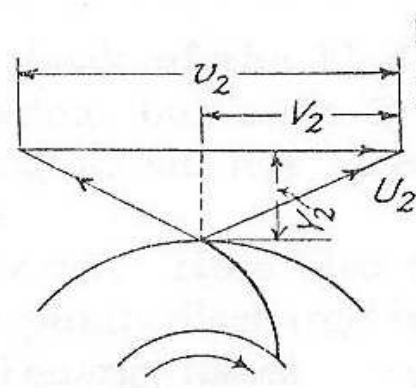

NORMAL

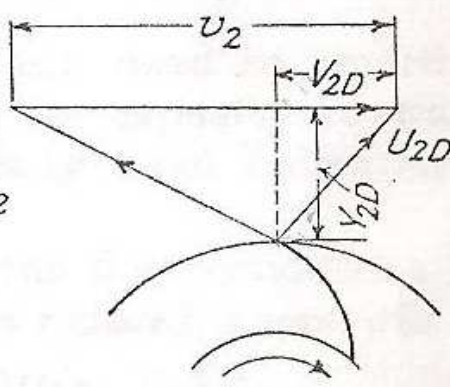

INCREASED

Ideal outlet velocity diagrams for reduced, normal, and increase flow in centrifugal pump impeller.

If now the pump discharge is considerably above normal, then the absolute velocity vector (figure 1) takes an abnormal inclination. Very serious contraction of main stream of liquid may occur at volute tongue (figure 2) with consequent energy losses.

In regard to guide blade or diffuser type recuperator(figure 3) shows that abnormally higher rates of flow will again destroy the necessary correspondence between vane inclination and velocity vector inclination. Energy dissipation is augmented here also
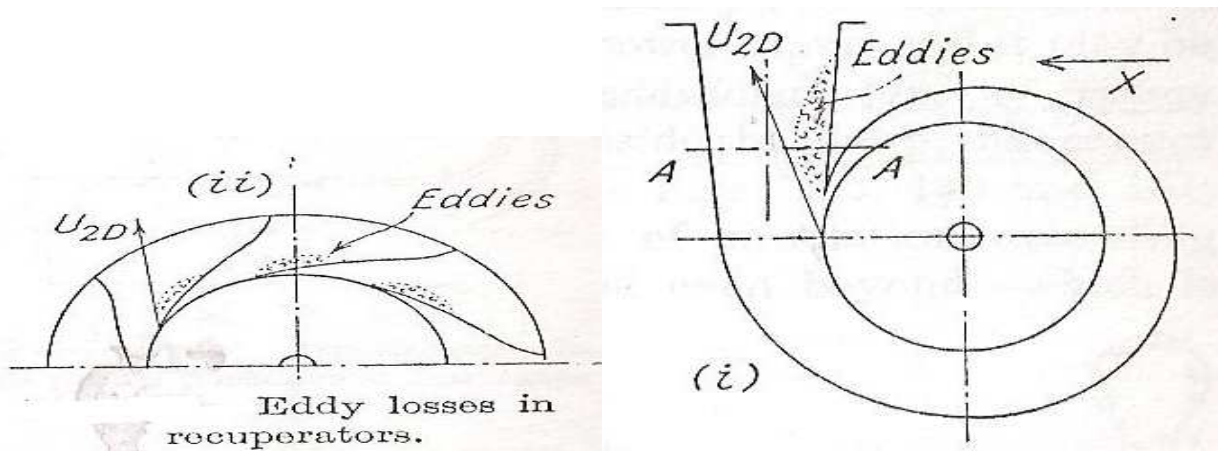

Fig. 3. 


\section{Operation at high flows}

The vast majority of pumping systems run far from their best efficiency point (BEP). For reasons ranging from shortsighted or overly conservative design, specification and procurement to decades of incremental changes in operating conditions, most pumps, pipes and control valves are too large or too small. In anticipation of future load growth, the enduser, supplier and design engineers routinely add 10 to $50 \%$ "safety margins" to ensure the pump and motor can accommodate anticipated capacity increases.

Under this circumstances the head capacity curve intersects the system head curve at a capacity much in excess of the required flow using excess power. Of course the pump can be throttled back to the required capacity and the power is reduced some what. But if the pump runs uncontrolled it will always run at excess flow. unless sufficient NPSH has been made available, the pump may suffer cavitation damage and power consumption will be excessive.Important energy savings can be made if at the time of selecting the condition of service, reasonable restraints are exercised to avoid using excessive safety margins for obtaining the rated service condition. But in an existing installation if the pumps have excessive margins the following options are available.

a. The existing impeller can be cut down to meet the condition of service required for the installation.

b. A replacement impeller with the necessary reduced diameter may be ordered from the pump manufacturer.

c. In certain cases there may be two separate impellers designs available for the same pump, one of which is of narrower width than the one originally furnished. A narrower replacement will have its best efficiency at at a lower capacity than the normal width impeller.

\subsection{Effect of speed and its control}

Speed of the centrifugal pump has marked effect on the varios losses taking place in the pump and hence it is also one the important factor which can be controlled tyo improve efficiency.

\subsection{Effect of speed on various losses}

Mechanical losses: In the pump the correlation between speed $\mathrm{N}$ and mechanical power loss $\mathrm{P}_{\mathrm{b}}$ will be

$$
\mathrm{P}_{\mathrm{b}}=\mathrm{K}_{1} \cdot \mathrm{Nm}
$$

The value of $\mathrm{m}$ is between $1 \& 2$ depending upon the type of bearing and stuffing box.

The input power varies as the cube of speed.

$$
\mathrm{P}_{\mathrm{S}}=\mathrm{K}_{2} \cdot \mathrm{N}^{3}
$$

So the relative mechanical loss $=\mathrm{P}_{\mathrm{b}} / \mathrm{P}_{\mathrm{s}}=\mathrm{K}_{1} . \mathrm{Nm}^{\mathrm{m}} / \mathrm{K}_{2} . \mathrm{N}^{3}$

Disc friction loss : For a given pump using liquid the relation between speed and power loss can be given by 


$$
\begin{aligned}
& \qquad \mathrm{P}_{\mathrm{d}}=\mathrm{K}_{3} . \mathrm{N} 2.85 \\
& \text { The relative disc friction loss }=\mathrm{P}_{\mathrm{d}} / \mathrm{P}_{\mathrm{s}}=\mathrm{K}_{3} . \mathrm{N}^{2.85} / / \mathrm{K}_{2} . \mathrm{N}^{3}
\end{aligned}
$$

It show that the value relative disc friction loss increases as the speed decreases.

Leakage: The relative leakage loss appears to be independent of the pump speed.The leakage takes place. It seems likely that the relative leakage power loss will slightly increase as the pump speed falls

Hydraulic Power loss: As the liquid flows at a rate $Q$ through the pump passage, it undergoes a energyu loss consist of friction loss and eddy losses.

The hydraulic power loss is denoted by

$$
\mathrm{P}_{\mathrm{h}}=\mathrm{K}_{11} \cdot \mathrm{N}^{2.95}
$$

Comparing this with the input power

$$
\Delta \mathrm{n}=\mathrm{K}_{11} . \mathrm{N}^{2.95} / \mathrm{K}_{2} . \mathrm{N}^{3}
$$

Hence the value of the relative power loss rises as the pump speed falls.

These kind of losses can be minimized by having a proper speed control mechanism.

Speed control is an option that can keep pumps operating efficiently over a broad range of flows. In centrifugal pumps, speed is linearly related to flow but has a cube relationship with power. For example, slowing a pump from 1800 to $1200 \mathrm{rpm}$ results in a 33\% decreased flow and a $70 \%$ decrease in power. This also places less stress on the system.

There are two types of speed control in pumps: multi-speed motors and variable speed drives. Multi-speed motors have discrete speeds (e.g., high, medium, and low). Variable speed drives provide speed control over a continuous range. The most common type is the variable frequency drive (VFD), which adjusts the frequency of the electric power supplied to the motor. VFDs are widely used due to their ability to adjust pump speed automatically to meet system requirements. For systems in which the static head represents a large portion of the total head, however, a VFD may be unable to meet system needs.

\section{Variable speed drives}

Pump over-sizing causes the pump to operate to the far left of its best efficiency point (BEP) on the pump head -capacity curve. Variable speed drives, assuming a low static head system, allow the pump to operate near its best efficiency point (BEP) at any head or flow. In addition, the drive can be programmed to protect the pump from mechanical damage when away from BEP -- thereby enhancing mechanical reliability. Furthermore, excessive valve throttling is expensive and not only contributes to higher energy and maintenance cost, but can also significantly impair control loop performance. Employing a throttled control valve, less than $50 \%$ open, on the pump discharge may accelerate component wear, thereby slowing valve response.

VFDs allow pumps to run at slower speeds with further contributions to pump reliability and significant improvement in mean-time-between-failure (MTBF). 


\section{Effect of specific speed}

The higher the specific speed selected for a given set of operating condition, the higher the pump efficiency and therefore the lower the power consumption. Barring other considerations the tendency should be to favour higher specific speed selection from the point of view of energy conservation

\subsection{Clearance}

Good wear ring with proper clearance improves pump reliability and reduce energy consumption. Correct impeller to volute or back plate clearance is also to be maintained. Pump efficiency decreases with time because of wear. A well designed pump usually comes with a diametral clearance of 0.2 to $0.4 \%$. however as long as it remains below 0.6 to $0.8 \%$ its effect on efficiency remains negligible. When the clearance start to increase beyond these values efficiency start to drop drastically. For equal operating condition the rate of wear depends primarily on design and material of the wear ring. Generally for non corrosive liquids, the resistance to wear increases with hardness of the sealing surface material.

If a pump having a specific speed of 2500 , the leakage loss in a new pump will be about $1 \%$. Thus when the internal clearances will have increased to the point that this leakage will have doubled, we can regain approximately $1 \%$ in power saving by restoring the pump clearance. But if we are dealing with a pump having a specific speed of 750 , it will have leakage loss of about $5 \%$. If the clearances are restored after the pump has worn to the point that its leakage losses have doubled, we can count on $5 \%$ power saving.

\subsection{Change in surface roughness}

Depending on the material of construction and properties of the liquid being pumped, the roughness of the flow path can also change over time. In some instances, the channels may acquire a smooth polish, and in other they may become roughened. Both of these changes can significantly affect pump performance. An increase in casing roughness usually reduces both the total head and the efficiency.

\subsection{Change in flow path size}

The dimension of the pump's flow path may change over time due to abrasion or erosion, which usually increases the pathways' dimension or to scale, rust or sedimentation which usually reduces the size of the pathways. The latter is particularly apt to occur in pumps operating intermittently.

\subsection{Run one pump instead of two}

Many installations are provided with two pumps operating in parallel to deliver the required flow under full load. Too often, both pumps are kept on line even when demand drops to a point where a single pump can carry the load. The amount of energy wasted in running two pumps at half load when a single pump can meet this condition is significant.

If we want to reduce the flow to half load and still maintain both pumps online, it will be necessary to throttle the pump discharge and create a new system head curve. Under these 
condition, each pump will deliver $50 \%$ of the rated capacity at $117 \%$ rated head, much of which will have to be throttled. Each pump will take $72.5 \%$ of its rated power consumption. Thus the total power consumption of two pumps of two pumps operating under half load condition would be $145 \%$ of that required if a single pump were to be kept on line.

\section{Viscosity of liquid}

Liquid viscosity affect pump performance. This is because two of the major losses in a centrifugal pump are caused by fluid friction and disc friction. These losses vary with the viscosity of the liquid being pumped, so that both the head capacity output and the mechanical output differ from the original values. As viscosity of the liquid increases the head developed by the pump decreases and the efficiency decreases. So in process industries it is required to maintain good insulation and steam tracing in the suction line of the pump.

\subsection{Effect of cavitation}

Due to cavitation the vapor bubbles are formed and these bubbles will modify the velocity distribution as well as the pressure distribution in the rotor passage. The effect of vapor pressure bubbles will virtually lower the density of the liquid; that is the pump behaves as if another liquid of less density were flowing through it. As the mean velocity of the fluid mixture is now at higher (for the weight per second is unchanged) the outlet velocity diagram tends to assume the distorted shape and shall lower the total head. The fall in density reduces the pressure generated.

Due to cavitation there will be loss of energy.

\subsection{Effect of change of density}

The pump develops the same head in meters of liquid independent of specific gravity. The pump delivers the same quantity by volume independent of specific gravity but the quantity by weight will be proportional to specific gravity. The input power and the output power for a given volumetric discharge vary in proportion to density.

If the water is heated the density changes. In high pressure steam boilers, the reduction in density of the water may be 15 percent or more. If a given weight per second of water is to be discharged against a stipulated pressure, the power output will increase as the water temperature increases.

\subsubsection{Pump sizing}

Selecting a centrifugal pump can be challenging because these pumps generate different amounts of flow at different pressures. Each centrifugal pump has a "best efficiency point" $(\mathrm{BEP})$. Ideally, under normal operating conditions, the required flow rate will coincide with the pump's BEP.

The complexity associated with selecting a pump often results in a pump that is improperly sized for its application. Selecting a pump that is either too large or too small can reduce system performance. Undersizing a pump may result in inadequate flow, failing to meet 
system requirements. An oversized pump, while providing sufficient flow, can produce other negative consequences; higher purchase costs for the pump and motor assembly; higher energy costs, because oversized pumps operate less efficiently; and higher maintenance requirements, because as pumps operate further from their BEP they experience greater stress; ironically, many oversized pumps are purchased with the intent of increasing system reliability.

Unfortunately, conservative practices often prioritize initial performance over system life cycle costs. As a result, larger-than-necessary pumps are specified, resulting in systems that do not operate optimally. Increased awareness of the costs of specifying oversized pumps should discourage this tendency.

\subsubsection{Variable loads}

In systems with highly variable loads, pumps that are sized to handle the largest loads may be oversized for normal operating loads. In these cases, the use of multiple pumps, multispeed motors, or variable speed drives often improves system performance over the range of operating conditions.

To handle wide variations in flow, multiple pumps are often used in a parallel configuration. This arrangement allows pumps to be energized and de-energized to meet system needs. One way to arrange pumps in parallel is to use two or more pumps of the same type. Alternatively, pumps with different flow rates can be installed in parallel and configured such that the small pump-often referred to as the "pony pump"-operates during normal conditions while the larger pump operates during periods of high demand.

\subsection{Valves and fittings}

Pumping system controls should be evaluated to determine the most economical control method. High-head-loss valves, such as globe valves, are commonly used for control purposes. Significant losses occur with these types of valves, however, even when they are fully open. If the evaluation shows that a control valve is needed, choose the type that minimizes pressure drop across the valve. Pumping system control valve inefficiencies in plant processes offer opportunities for energy savings and reduced maintenance costs. Valves that consume a large fraction of the total pressure drop for the system, or are excessively throttled, can be opportunities for energy savings. Pressure drops or head losses in liquid pumping systems increase the energy requirements of these systems. Pressure drops are caused by resistance or friction in piping and in bends, elbows, or joints, as well as by throttling across the control valves. The power required to overcome a pressure drop is proportional to both the fluid flow rate (given in gallons per minute [gpm]) and the magnitude of the pressure drop (expressed in $\mathrm{ft}$ of head). The friction loss and pressure drop caused by fluids flowing through valves and fittings depend on the size and type of pipe and fittings used, the roughness of interior surfaces, and the fluid flow rate and viscosity.

Case study 1 -

In the Hydrocracker Unit of a petroleum refinery the reflux pump generally pumps Naptha with a specific gravity of 0.7 . The motor KW rating was $190 \mathrm{kw}$. Due to some adverse 
situation in the process, sometimes water also comes in the stream resulting in increase of specific gravity of 0.9 . As power $\mathrm{P}=(\mathrm{wQH} / 3960)$ where $\mathrm{w}$ is specific weight, $\mathrm{Q}$ is discharge and $\mathrm{H}$ is the manometric head As a result the motor draws more current. If it goes unnoticed the energy will be wasted.

Case study 2 -

The pump develops the same head in meters of liquid independent of specific gravity. The pump delivers the same quantity by volume independent of specific gravity but the quantity by weight will be proportional to specific gravity. The input power and the output power for a given volumetric discharge vary in proportion to density.

In the Vacuum Distillation Unit of a petroleum refinery the column bottom pump pumps Short residue with a specific gravity of approximately 0.9. Most of the refinery are configured for different type of crudes, like high sulphur and low sulphur. During processing of high sulphur crude the specific gravity and viscosity of the short residue increases. This results in more power consumption.

Case study 3 -

In systems with highly variable loads, pumps that are sized to handle the largest loads may be oversized for normal operating loads. In these cases, the use of multiple pumps, multispeed motors, or variable speed drives often improves system performance over the range of operating conditions.

To handle wide variations in flow, multiple pumps are often used in a parallel configuration. This arrangement allows pumps to be energized and de-energized to meet system needs. One way to arrange pumps in parallel is to use two or more pumps of the same type. Alternatively, pumps with different flow rates can be installed in parallel and configured such that the small pump operates during normal conditions while the larger pump operates during periods of high demand.

In the Crude unit of a petroleum refinery the main crude pumps are installed in parallel. Some times the crude unit thru put depends upon the secondary unit thruput. If there is any disturbance in the secondary units, then the load in the Crude unit has to brought down. In this case multiple pumps are used in a parallel configuration. This arrangement allows saving energy.

Case study 4 -

The dimension of the pump's flow path may change over time due to scale, rust or sedimentation which usually reduces the size of the pathways. The latter is particularly apt to occur in pumps operating intermittently.

The sulphur pit pump in a Sulphur recovery unit operates intermittently. It pumps liquid sulphur in a jacketed pipe. If the steam in the jacket is not circulated properly or due to ageing, some sulphur particles get deposited in the line. This reduces the flow path size. An increase in pipe roughness increases the friction loss and usually reduces the efficiency. Because of these reasons the pump started drawing more power and tripped more frequently. So to avoid the deposition of sulphur in the line steam was injected so as to clean the sulphur line. 


\section{Conclusion}

The following are different ways to conserve the Energy in Pumping System:

- When actual operating conditions are widely different (head or flow variation by more than 25 to $30 \%$ ) than design conditions, replacements by appropriately sized pumps must be considered.

- Operating multiple pumps in either series or parallel as per requirement.

- Reduction in number of pumps (when System Pressure requirement, Head and Flow requirement is less).

- $\quad$ By improving the piping design to reduce Frictional Head Loss

- By reducing number of bends and valves in the piping system.

- By avoiding throttling process to reduce the flow requirement.

- By Trimming or replacing the Impellers when capacity requirement is low.

- $\quad$ By using Variable Speed Drives

\section{References}

[1] "Trouble shooting Process Operations", 3rd Edition 1991, Norman P.Lieberman, PennWell Books

[2] "Centrifugal pumps operation at off-design conditions", Chemical Processing April,May, June 1987, Igor J. Karassik

[3] "Understanding NPSH for Pumps", Technical Publishing Co. 1975, Travis F. Glover

[4] "Centrifugal Pumps for General Refinery Services", Refining Department, API Standard 610, 6th Edition, January 1981

[5] "Controlling Centrifugal Pumps", Hydrocarbon Processing, July 1995, Walter Driedger 


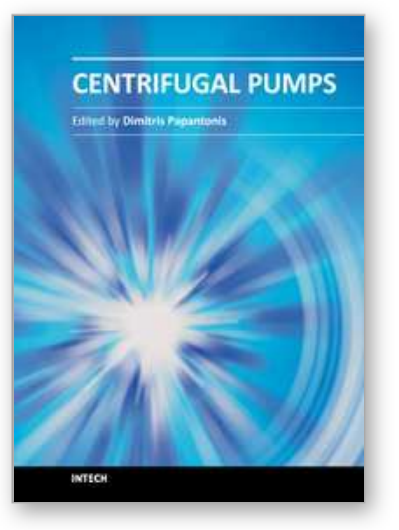

\author{
Centrifugal Pumps \\ Edited by Dr. Dimitris Papantonis
}

ISBN 978-953-51-0051-5

Hard cover, 106 pages

Publisher InTech

Published online 24, February, 2012

Published in print edition February, 2012

The structure of a hydraulic machine, as a centrifugal pump, is evolved principally to satisfy the requirements of the fluid flow. However taking into account the strong interaction between the pump and the pumping installation, the need to control the operation, the requirement to operate at best efficiency in order to save energy, the provision to improve the operation against cavitation and other more specific but very interesting and important topics, the object of a book on centrifugal pumps must cover a large field. The present book examines a number of these more specific topics, beyond the contents of a textbook, treating not only the pump's design and operation but also strategies to increase energy efficiency, the fluid flow control, the fault diagnosis.

\title{
How to reference
}

In order to correctly reference this scholarly work, feel free to copy and paste the following:

Trinath Sahoo (2012). Strategies to Increase Energy Efficiency of Centrifugal Pumps, Centrifugal Pumps, Dr. Dimitris Papantonis (Ed.), ISBN: 978-953-51-0051-5, InTech, Available from:

http://www.intechopen.com/books/centrifugal-pumps/strategies-to-increase-energy-efficiency-of-centrifugalpumps

\section{INTECH}

open science | open minds

\section{InTech Europe}

University Campus STeP Ri

Slavka Krautzeka 83/A

51000 Rijeka, Croatia

Phone: +385 (51) 770447

Fax: +385 (51) 686166

www.intechopen.com
InTech China

Unit 405, Office Block, Hotel Equatorial Shanghai

No.65, Yan An Road (West), Shanghai, 200040, China

中国上海市延安西路65号上海国际贵都大饭店办公楼405单元

Phone: +86-21-62489820

Fax: +86-21-62489821 
(C) 2012 The Author(s). Licensee IntechOpen. This is an open access article distributed under the terms of the Creative Commons Attribution 3.0 License, which permits unrestricted use, distribution, and reproduction in any medium, provided the original work is properly cited. 